\title{
Kinematic Simulation of Telescopic Sleeve Anti-Swing Device Based on Ship Swing
}

\author{
Guangdong Hanª, Haiquan Chen, Shenghai Wang, Jinnan Zhang \\ College of Marine Engineering, Dalian Maritime University, Dalian, China \\ a18842602951@163.com
}

Keywords: shipboard crane, Telescopic sleeve device, Adams, Simulation.

\begin{abstract}
In order to reduce the impacts of wave on ship-mounted crane during operating the crane under rough weather conditions. A new type of shipboard crane telescopic sleeve anti-swing device was proposed. It uses the rigid constraints of the sleeve to reduce the swing range of the load, and through the universal torque damping mechanism to reduce stress on the telescopic sleeve. The form and principle telescopic sleeve device was introduced. A mathematical model of the ship and crane is established. Establish the simulation model by Adams, the load swing angle with having telescopic sleeve and without telescopic sleeve were achieved respectively under ship swing. At the end, the swing angle of these two models were analyzed according to the simulation results. Verify the telescopic sleeve device has a significant effect on anti-swing.
\end{abstract}

\section{Introduction}

When the ship is working at sea, the ship will produce rolling, pitching, yawing, swaying, surging, heaving motion in six degrees of freedom, due to the influence of wind, wave and drift. It is impossible to carry out the job when the sea conditions are badly. The anti-swing technology of the crane has a broad application prospect in the offshore hoisting operation.

On the issue of anti-swing of crane, the main research includes mechanical and intelligent anti-swing method. Maryland Rigging System ${ }^{[1]}$ established the linear dynamic model of ship crane by Lagrange method. Yuewei $\mathrm{Li}^{[2]}$ compared commonly used anti-swing mechanism. PARKER and others ${ }^{[3]}$ used the Rider Block Tagline System to control the pendulation of the load. Its structure and control are simple compared with the Maryland Rigging System. But when the rope length is longer, its function is restricted. JANG and others ${ }^{[4]}$ established the dynamic model of container ship crane, and used T-S fuzzy control method to control the swing of load. Ismail and others ${ }^{[5]}$ established the three degree of freedom model of marine rotary boom crane, and used two order sliding model to control to realize the tracking and anti-swing. Pengcheng Wang and others ${ }^{[6]}$ make dynamic analysis and established the model of marine rotary boom crane. Yongchun Fang and others ${ }^{[7]}$ designed nonlinear controller depend on the Pengcheng Wang's model and simulation tested.

Combined with the present situation and the actual situation of the vessel. This paper presents a kind of telescopic sleeve anti-swing device. Established the kinematic model of ship and crane. According to the model, analyzed the influence of the ship motion on the crane and the stress of the telescopic sleeve device. And used the Adams to do simulation experiment. Verify the telescopic sleeve device has a good effect of anti-swing.

\section{Principle of anti-swing}

The telescopic sleeve device is composed of a universal torque structure and a telescopic sleeve. Telescopic sleeve device is shown in Fig.1. The anti-swing principle of telescopic sleeve device is shown in Fig.2. When Crane boom hoisting and luffing by the adjustment of the hydraulic oil cylinder. The sleeve is always in a vertical downward state. When crane working, the rolling and pitching of the ship caused by waves make the load pendulation. At this time, because the rope through the telescopic sleeve device, the telescopic sleeve will bear a part of wave load, and transfer to the spherical hinge which connected with the telescopic sleeve. Three dampers of the universal torque 
structure will offset the torque which transfer by spherical hinge to weaken the pendulation of the telescopic sleeve. So as to achieve the purpose of anti-swing.
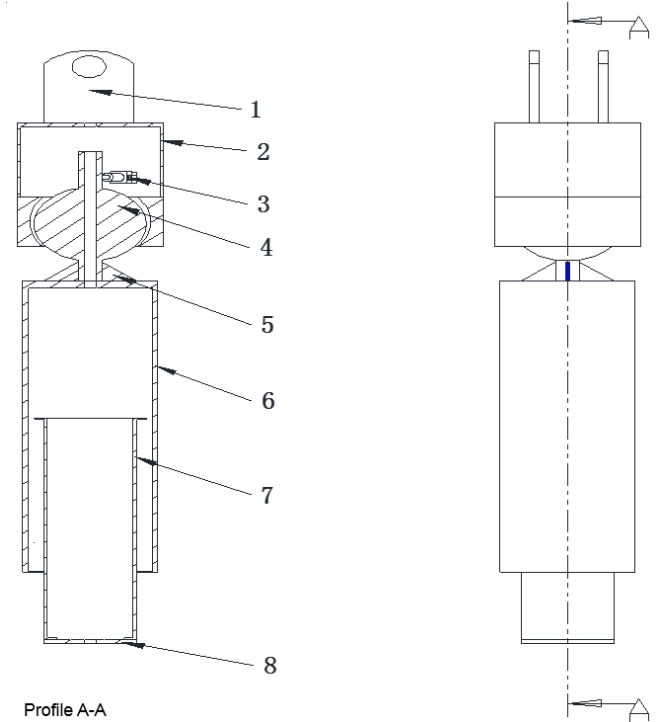

Fig.1 The structure of the telescopic casing device

1.Lug; 2.Cylinder; 3.Damper; 4.spherical hinge; 5.Connecting plate; 6.Outer pipe; 7. Inner tube; 8.

End cap

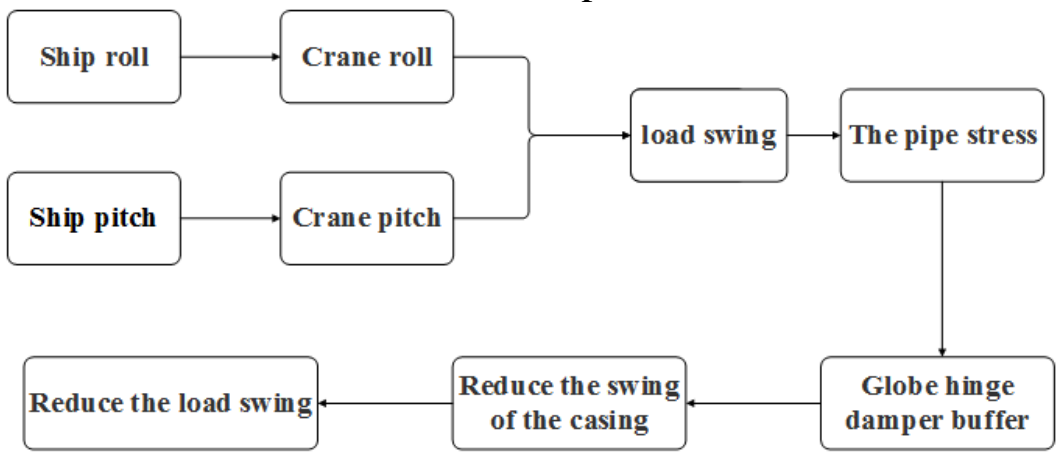

Fig.2 The anti-swing principle of the telescopic sleeve device

\section{Kinematic model}

In order to achieve the purpose of reducing the pendulation of the telescopic sleeve, we first establish the kinematic model of the telescopic sleeve, and use the Denavit-Hartenberg method to model the system. The models of the ship and crane, and the balance torque model of the telescopic sleeve are established.

\subsection{Ship and crane model}

Ship and crane model is shown in Fig.3. The corresponding connecting rod parameters are shown in Tab.1. Where $\{\mathrm{B}\}$ is the ship coordinate, $Z_{\mathrm{B}}$ is the vertical direction, $X_{\mathrm{B}}$ is the beam direction, $Y_{\mathrm{B}}$ is the length direction, $\{0\}$ is crane base coordinate $\{1\},\{2\}$ are corresponding to the crane rotary joint, variable amplitude joint, $\theta_{1}$ and $\theta_{2}$ respects the two joints. The origin of the coordinate $\{2\}$ corresponds to the crane lifting point, $L_{1}$ is the height of basic, $L_{2}$ is the length of crane arm. 


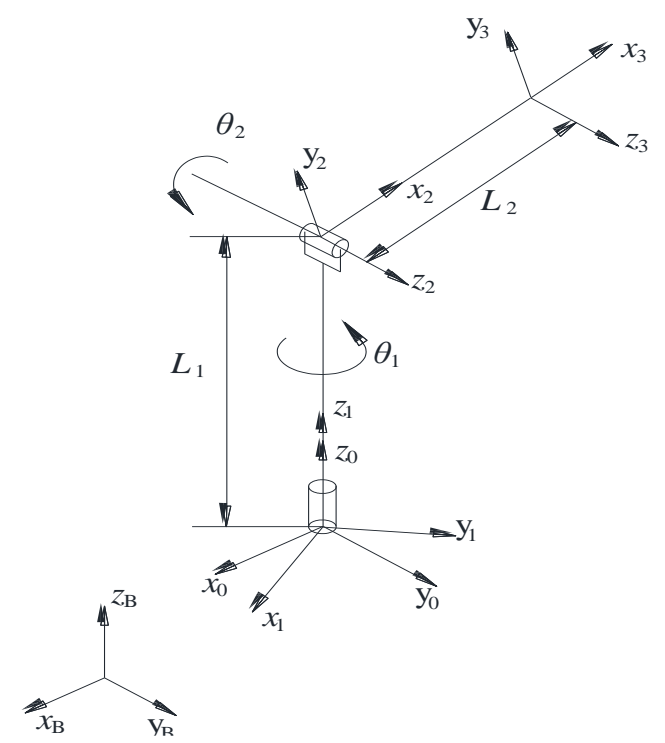

Fig.3 Ship and crane model

Table. 1 connecting rod parameters

\begin{tabular}{ccccc}
\hline$i$ & $\alpha_{\mathrm{i}-1}$ & $a_{\mathrm{i}-1}$ & $d_{\mathrm{i}}$ & $\theta_{\mathrm{i}}$ \\
\hline 1 & 0 & 0 & 0 & $\theta_{1}$ \\
2 & -90 & 0 & $L_{1}$ & $\theta_{2}$ \\
3 & 0 & $L_{2}$ & 0 & 0 \\
\hline
\end{tabular}

Coordinate $\{\mathrm{i}\}$ relative to the coordinate system transform for $\{\mathrm{i}-1\}$.

$$
{ }_{i}^{i-1} T=\left[\begin{array}{cccc}
\mathrm{c} \theta_{i} & -\mathrm{s} \theta_{i} & 0 & a_{i-1} \\
\mathrm{~s} \theta_{i} \mathrm{c} \alpha_{i-1} & \mathrm{c} \theta_{i} \mathrm{c} \alpha_{i-1} & -\mathrm{s} \alpha_{i-1} & -\mathrm{s} \alpha_{i-1} d_{i} \\
\mathrm{~s} \theta_{i} \mathrm{~s} \alpha_{i-1} & \mathrm{c} \theta_{i} \mathrm{~s} \alpha_{i-1} & \mathrm{c} \alpha_{i-1} & \mathrm{c} \alpha_{i-1} d_{i} \\
0 & 0 & 0 & 1
\end{array}\right]
$$

The transformation matrix of the coordinate $\{3\}$ relative to the coordinate $\{0\}$ is:

${ }_{3}^{0} T={ }_{1}^{0} T{ }_{2}^{1} T{ }_{3}^{2} T$

The transformation matrix of the coordinate $\{0\}$ relative to the ship coordinate $\{\mathrm{B}\}$ is:

$$
{ }_{0}^{B} T=\left[\begin{array}{cccc}
1 & 0 & 0 & B_{x} \\
0 & 1 & 0 & B_{y} \\
0 & 0 & 1 & B_{z} \\
0 & 0 & 0 & 1
\end{array}\right]
$$

Where $(\mathrm{Bx}, \mathrm{By}, \mathrm{Bz})$ for the coordinate $\{0\}$ origin in the coordinates of the ship coordinate $\{\mathrm{B}\}$.

If the ship is located at the static sea level, the inertial coordinate $\{N\}$ and the ship coordinate $\{B\}$. When the wind and waves flow disturbed the ship rolling and pitching. The transformation matrix of the coordinate $\{\mathrm{B}\}$ relative to the inertial coordinate $\{\mathrm{N}\}$ is:

$$
{ }_{B}^{N} T=\left[\begin{array}{cccc}
\cos \alpha \cos \beta & -\sin \alpha & \cos \alpha \sin \beta & 0 \\
\cos \beta \sin \alpha & \cos \alpha & \sin \alpha \sin \beta & 0 \\
-\sin \beta & 0 & \cos \beta & 0 \\
0 & 0 & 0 & 1
\end{array}\right]
$$

The $\alpha$ is the roll angle and the $\beta$ is the pitch angle.

By Eq.2, Eq.3, Eq.4 can get the transformation matrix of coordinate $\{3\}$ relate to the inertial coordinate $\{\mathrm{N}\}$

$$
{ }_{3}^{N} T={ }_{B}^{N} T_{0}^{B} T_{3}^{0} T=\left[\begin{array}{cccc}
r_{11} & r_{12} & r_{13} & p_{x} \\
r_{21} & r_{22} & r_{23} & p_{y} \\
r_{31} & r_{32} & r_{33} & p_{z} \\
0 & 0 & 0 & 0
\end{array}\right] .
$$


Put the corresponding parameters in Table 1 to the Eq.1, Eq.2, Eq.3, Eq.4, Eq.5 can get:

$P_{x}=B_{x} \mathrm{c} \alpha \mathrm{c} \beta-B_{y} \mathrm{~s} \alpha+B_{z} \mathrm{c} \alpha \mathrm{s} \beta-L_{1}\left(\mathrm{c} \theta_{1} \mathrm{~s} \alpha+\mathrm{c} \alpha \mathrm{c} \beta \mathrm{s} \theta_{1}\right)+L_{2}\left(\mathrm{c} \theta_{2}\left(\mathrm{c} \alpha \mathrm{c} \beta \mathrm{c} \theta_{1}-\mathrm{s} \alpha \mathrm{s} \theta_{1}\right)-\mathrm{c} \alpha \mathrm{s} \beta \mathrm{s} \theta_{2}\right)$

$P_{y}=B_{y} \mathrm{c} \alpha+B_{x} \mathrm{c} \beta \mathrm{s} \alpha+B_{z} \mathrm{~s} \alpha \mathrm{s} \beta+L_{1}\left(\mathrm{c} \alpha \mathrm{c} \theta_{1}-\mathrm{c} \beta \mathrm{s} \alpha \mathrm{s} \theta_{1}\right)+L_{2}\left(\mathrm{c} \theta_{2}\left(\mathrm{c} \beta \mathrm{c} \theta_{1} \mathrm{~s} \alpha+\mathrm{c} \alpha \mathrm{s} \theta_{1}\right)-\mathrm{s} \alpha \mathrm{s} \beta \mathrm{s} \theta_{2}\right)$

$P_{z}=B_{z} \mathrm{c} \beta-B_{x} \mathrm{~s} \beta+L_{1} \mathrm{~s} \beta \mathrm{s} \theta_{1}-L_{2}\left(\mathrm{c} \theta_{1} \mathrm{c} \theta_{2} \mathrm{~s} \beta+\mathrm{c} \beta \mathrm{s} \theta_{2}\right)$

$P x, P y, P z$ for the lifting point relative to the inertial coordinate $\{\mathrm{N}\}$ of the roll, pitch, heave.

In order to realize anti-sway expression is expressed as:

$\theta_{1} \rightarrow-\alpha ; \theta_{2} \rightarrow-\beta$

\subsection{Torque balance model of telescopic sleeve device}

Torque balance model is shown in Fig.4. $\mathrm{X}$ is the length direction, $\mathrm{Y}$ is the beam direction, $\mathrm{Z}$ is the vertical height. $L_{1}$ is the rod length between the upper end of the spherical joint and the damper joint. $\mathrm{L}_{2}$ is the rod length between the upper end of the spherical joint and the end of the telescopic sleeve. $\mathrm{F}$ for damper resistance, $\mathrm{G}$ is the force of gravity, $\mathrm{F}_{1}, \mathrm{~F}_{2}, \mathrm{~F}$ component for $\mathrm{G}$ in the vertical direction and sleeve, the $\alpha$ is the angle between the sleeve and the $\mathrm{Z}$ axis, the $\beta$ is the angle between the sleeve and the $\mathrm{X}$ axis.

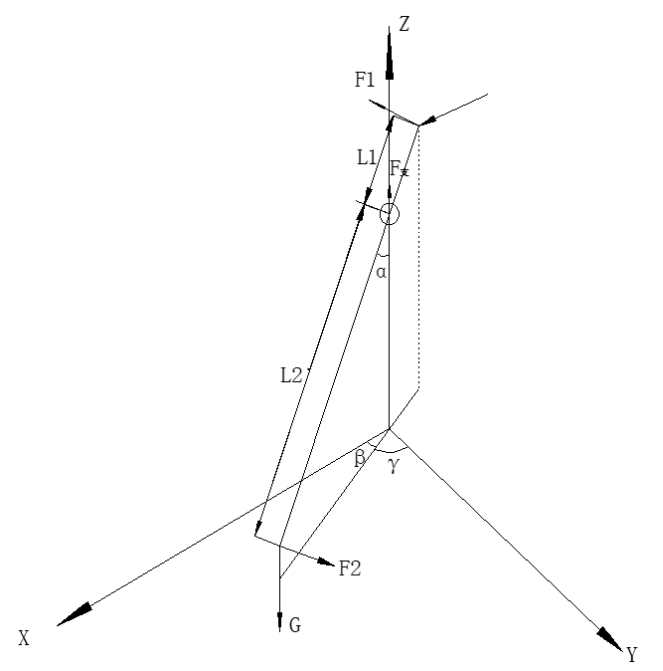

Fig.4 Torque balance model

In order to achieve the torque balance, the main vector and force of the torque are equal to zero at any point. Showed through analysis method:

$\sum m_{x}(F)=0 ; \sum m_{y}(F)=0 ; \sum m_{z}(F)=0$

In order to $\sum m_{x}(F)=0$. So

$$
F_{X 1} L_{X 1}=F_{X 2} L_{X 2}
$$

Because the force $\mathrm{F}$ is provided by the damper force and it always vertical to $\mathrm{Z}$ axis, and the reaction force of the damper is always opposite to the sleeve movement direction. So:

$$
F_{X 2}=F \cos ^{2} \alpha \cos ^{2} \beta ; L_{X 2}=L_{2} \cos ^{2} \alpha \cos ^{2} \beta
$$

Because the gravity $\mathrm{G}$ is always downward, and the Tangential stress of the casing is always perpendicular to the casing.so:

$F_{X 1}=G \sin \alpha \cos \alpha \cos \beta ; L_{X 1}=L 1 \sin \alpha \cos \alpha \cos \beta$

In summary

$F L_{2} \cos ^{2} \alpha \cos \beta=G L_{1} \sin \alpha \cos \alpha \cos \beta ; F L_{1} \cos \alpha=G L_{2} \sin \alpha$

Similarly $\Sigma m_{y}(F)=0$. So

$F L_{2} \cos ^{2} \alpha \sin \beta=G L_{2} \sin \alpha ; F L_{1} \cos \alpha=G L_{2} \sin \alpha$

Similarly $\Sigma m_{z}(F)=0$. So

$$
F_{Z}=G \sin ^{2} \alpha=F_{\text {branch }}
$$


In summary, in order to achieve anti-swing, the ship roll angle $\alpha$, pitch angle $\beta$ meet Eq.9, the force of telescopic sleeve device meet Eq.14, Eq.15, Eq.16.

\section{Simulation analysis}

Complete the three-dimensional modeling and assembly of the parts in SOLIDWORKS, then import the model into ADAMS. Create motion pairs for each joint. The simulation model is shown in Fig.5.

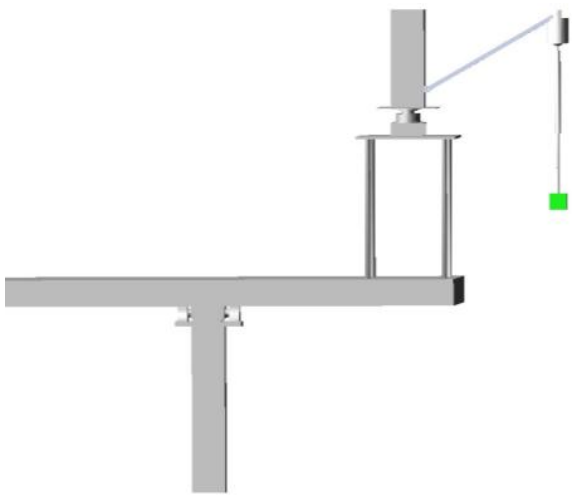

a. With sleeve

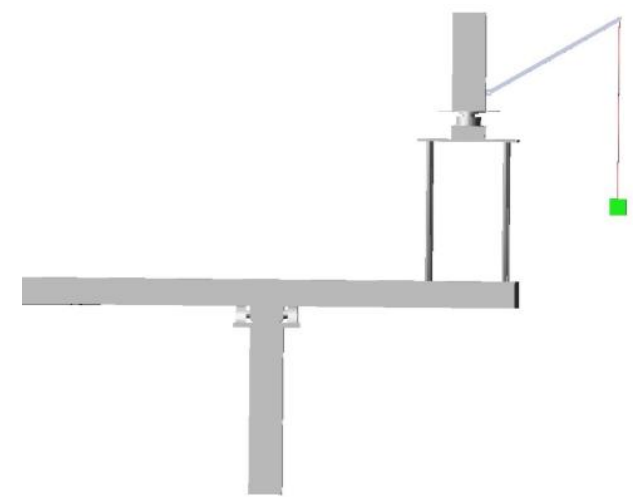

b. Without sleeve

Figure.5 The simulation model

With the crane doesn't move, use the four freedom of the roll platform to simulate the movement of the ship. Set the pendulum length as $62.5 \mathrm{~cm}, 84 \mathrm{~cm}$ and $108 \mathrm{~cm}$, and carry out simulation with sleeve and without sleeve respectively. The simulation parameters are shown in Tab. 2.

Table.2 Simulation parameters

\begin{tabular}{|c|c|c|c|c|}
\hline & Group & Roll/Pitch & Pendulum length/cm & With/without sleeve \\
\hline \multirow{5}{*}{ Experiment } & E1 & Roll & 62.5 & Without \\
\cline { 2 - 5 } & E2 & Roll & 62.5 & With \\
\cline { 2 - 5 } & E3 & Roll & 84 & Without \\
\cline { 2 - 5 } & E4 & Roll & 84 & With \\
\cline { 2 - 5 } & E5 & Roll & 108 & Without \\
\cline { 2 - 5 } & E6 & Roll & 108 & With \\
\hline & E7 & Pitch & 62.5 & Without \\
\cline { 2 - 5 } & E8 & Pitch & 62.5 & With \\
\cline { 2 - 5 } & E9 & Pitch & 84 & Without \\
\cline { 2 - 5 } & E10 & Pitch & 84 & With \\
\cline { 2 - 5 } & E11 & Pitch & 108 & Without \\
\cline { 2 - 5 } & E12 & Pitch & 108 & With \\
\hline
\end{tabular}

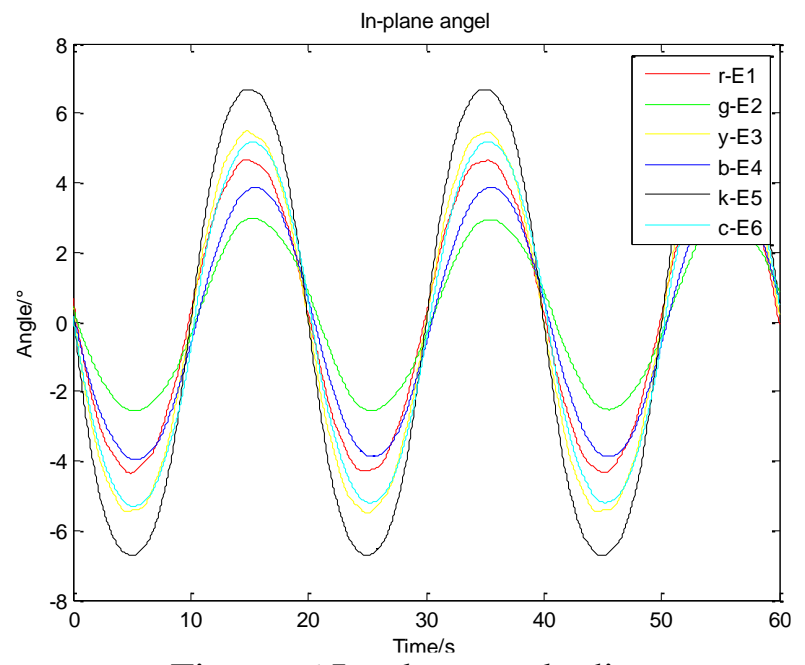

Figure. 6 In-plane angle diagram

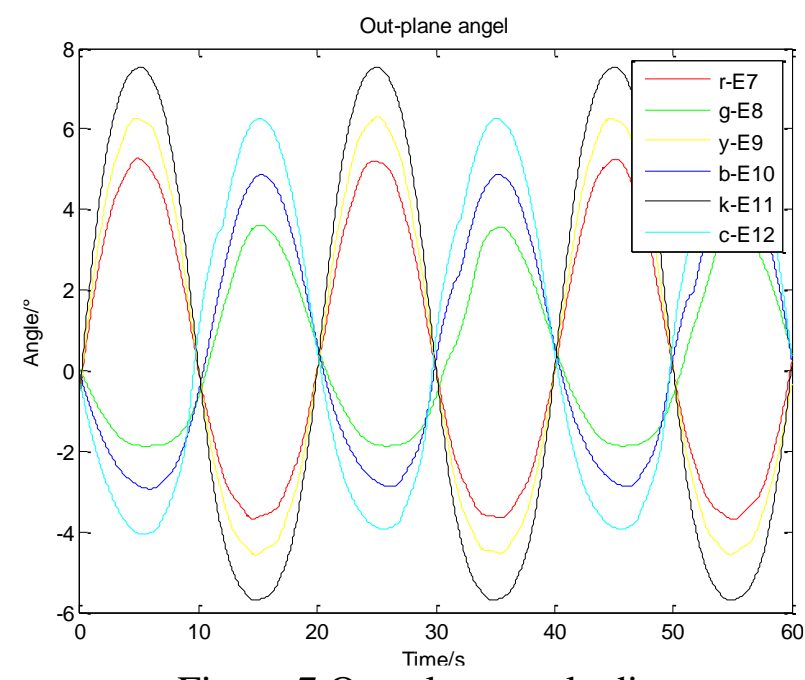

Figure.7 Out-plane angle diagram 


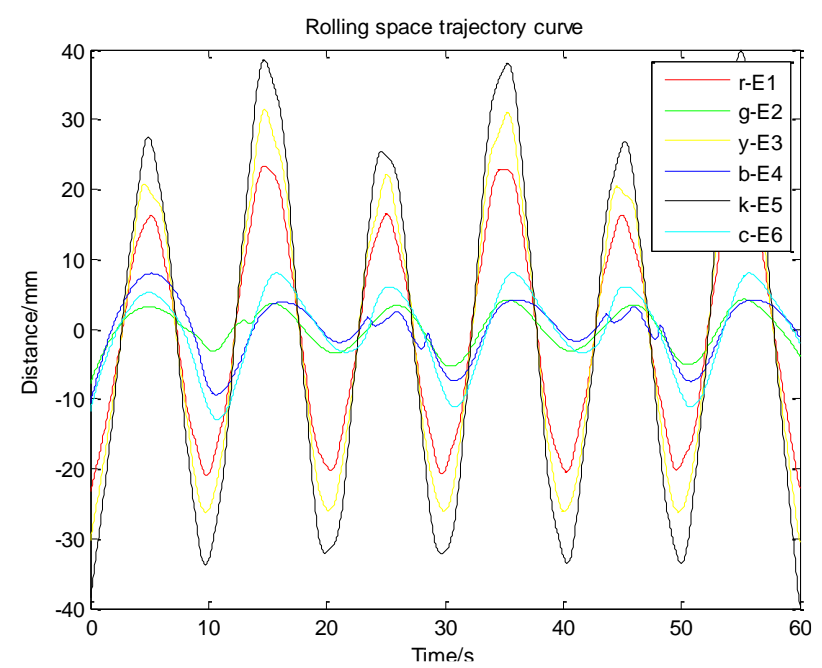

Figure.8 Rolling space trajectory curve

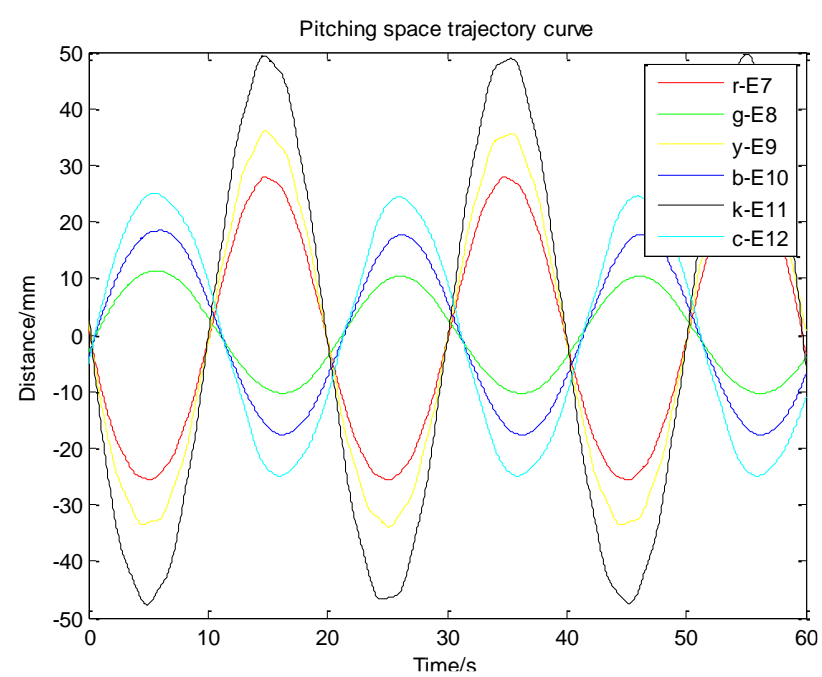

Figure.9 Pitching space trajectory curve

Get the simulation experiment results of Fig.6, Fig.7, Fig.8 and Fig.9, respectively in-plane angle and out-plane angle and space trajectory of with and without sleeve were analyzed. In roll platform rolling cases, the results shown in Tab.3 and Tab.4. In roll platform pitching cases, the results shown in Tab.5 and Tab.6.

Table. 3 In-plane angle simulation result

\begin{tabular}{|c|c|c|c|c|c|}
\hline $\begin{array}{c}\text { Experiment } \\
\text { number }\end{array}$ & $\begin{array}{c}\text { Rolling/ } \\
\left({ }^{\circ}\right) \cdot \mathrm{s}-1\end{array}$ & $\begin{array}{c}\text { pendulum } \\
\text { length/cm }\end{array}$ & $\begin{array}{c}\text { With/without } \\
\text { sleeve }\end{array}$ & $\begin{array}{c}\text { maximum pendulum } \\
\text { angle/ }\end{array}$ & $\begin{array}{c}\text { Reduction } \\
\text { ratio/\% }\end{array}$ \\
\hline 1 & 3.25 & 62.5 & With & 2.2 & \multirow{2}{*}{46.3} \\
\hline 2 & 3.25 & 62.5 & Without & 4.1 & \multirow{2}{*}{33.3} \\
\hline 3 & 3.25 & 84 & With & 3.2 & \multirow{2}{*}{30.2} \\
\hline 4 & 3.25 & 84 & Without & 4.8 & 4.4 \\
\hline 5 & 3.25 & 108 & With & 6.3 & \\
\hline 6 & 3.25 & 108 & Without & \multicolumn{5}{c}{} \\
\hline
\end{tabular}

Table.4 Rolling space trajectory simulation result

\begin{tabular}{|c|c|c|c|c|c|}
\hline $\begin{array}{c}\text { Experiment } \\
\text { number }\end{array}$ & $\begin{array}{c}\text { Rolling/ } \\
\left({ }^{\circ}\right) \cdot \mathrm{s}-1\end{array}$ & $\begin{array}{c}\text { pendulum } \\
\text { length/cm }\end{array}$ & $\begin{array}{c}\text { With/without } \\
\text { sleeve }\end{array}$ & $\begin{array}{c}\text { Maximum } \\
\text { amplitude/mm }\end{array}$ & $\begin{array}{c}\text { Reduction } \\
\text { ratio/\% }\end{array}$ \\
\hline 1 & 3.25 & 62.5 & With & 4.2 & \multirow{2}{*}{82.4} \\
\hline 2 & 3.25 & 62.5 & Without & 23.8 & \multirow{2}{*}{79.4} \\
\hline 3 & 3.25 & 84 & With & 6.1 & \multirow{2}{*}{78.3} \\
\hline 4 & 3.25 & 84 & Without & 29.6 & 8.4 \\
\hline 5 & 3.25 & 108 & With & 38.7 & \\
\hline 6 & 3.25 & 108 & Without & &
\end{tabular}

Table.5 Out-plane angle simulation result

\begin{tabular}{|c|c|c|c|c|c|}
\hline $\begin{array}{c}\text { Experiment } \\
\text { number }\end{array}$ & $\begin{array}{c}\text { pitching/ } \\
\left({ }^{\circ}\right) \cdot \mathrm{s}-1\end{array}$ & $\begin{array}{c}\text { pendulum } \\
\text { length/cm }\end{array}$ & $\begin{array}{c}\text { With/without } \\
\text { sleeve }\end{array}$ & $\begin{array}{c}\text { maximum pendulum } \\
\text { angle/ }\end{array}$ & $\begin{array}{c}\text { Reduction } \\
\text { ratio/\% }\end{array}$ \\
\hline 1 & 3.25 & 62.5 & With & 2.5 & \multirow{2}{*}{40.5} \\
\hline 2 & 3.25 & 62.5 & Without & 4.2 & \multirow{2}{*}{25.5} \\
\hline 3 & 3.25 & 84 & With & 3.8 & \multirow{2}{*}{21.0} \\
\hline 4 & 3.25 & 84 & Without & 5.1 & 4.9 \\
\hline 5 & 3.25 & 108 & With & 6.2 & \\
\hline 6 & 3.25 & 108 & Without & \multicolumn{3}{c}{} \\
\hline
\end{tabular}


Table.6 Pitching space trajectory simulation result

\begin{tabular}{|c|c|c|c|c|c|}
\hline $\begin{array}{c}\text { Experiment } \\
\text { number }\end{array}$ & $\begin{array}{c}\text { Rolling/ } \\
\left({ }^{\circ}\right) \cdot \mathrm{s}-1\end{array}$ & $\begin{array}{c}\text { pendulum } \\
\text { length/cm }\end{array}$ & $\begin{array}{c}\text { With/without } \\
\text { sleeve }\end{array}$ & $\begin{array}{c}\text { Maximum } \\
\text { amplitude/mm }\end{array}$ & $\begin{array}{c}\text { Reduction } \\
\text { ratio/\% }\end{array}$ \\
\hline 1 & 3.25 & 62.5 & With & 10.9 & \multirow{2}{*}{62.8} \\
\hline 2 & 3.25 & 62.5 & Without & 29.3 & \multirow{2}{*}{55.3} \\
\hline 3 & 3.25 & 84 & With & 17.6 & \multirow{2}{*}{48.1} \\
\hline 4 & 3.25 & 84 & Without & 39.4 & 25.5 \\
\hline 5 & 3.25 & 108 & With & 49.1 & \\
\hline
\end{tabular}

Compared with the rolling and pitching at each pendulation length. It can be concluded that the reduction ratio of the telescopic sleeve device is about $30 \%$. This shows that the telescopic sleeve device has an obviously anti-swing effect. The change of the space trajectory also verify the telescopic sleeve device can meet the need work condition of shipboard crane.

\section{Conclusion}

Get the requirement of anti-swing and force balance relation of telescopic sleeve device through the establishment of telescopic sleeve kinematic model. Under the rolling and pitching condition of the roll platform, using Adams to simulate the telescopic sleeve device. Concluded the pendulation angle with sleeve and without angle. It can improve that the telescopic sleeve device has an obviously anti-swing effect and meet the need work condition of shipboard crane.

\section{Acknowledgements}

The project supported by the Special funds for basic scientific research business of the Central University (3132014345); Liaoning Natural Science Foundation of China (2015020132).

\section{References}

[1] WEN B, HOMAIFAR A, BIKDASH M, KIMIAGHALAM B. Modeling and optimal control of shipboard crane[C]. In proceedings of IEEE, American control conference, San Diego, CA, June 2-4, 1999: 593-597.

[2] Kimiaghalam B, Homaifar A, Sayrrodsari B. An application of model predictive control for a shipboard crane[C]. Proceedings of the 2001 American Control Conference, Arlington, USA, June, 2001:929-934.

[3] Yuewei Li. Analysis of anti-sway system for crane [J].2009(9):51-53.

[4] Parker G, Graziano M, Leban F, et al. Reducing Crane Payload Swing Using A Rider Block Tagline Control System [J]. OCEANSE, Aberdeen, June, 2007:1-5.

[5] Jang Jae Hoon, Kwon Sung-Ha, Jeung Eun Tae. Pendulation reduction on ship -mounted container crane via T-S fuzzy model [J]. J. Cent. South Univ., 2012 (19):163-167.

[6] R.M.T. Raja Ismail, Q. P. HaTrajectory. Tracking and Anti-sway Control of Three-dimensional Offshore Boom Cranes Using Second-order Sliding Modes[C]. IEEE International Conference on Automation Science and Engineering (CASE), Madison, WI, 17-20 Aug, 2013:996-1001.

[7] Yongchun Fang, Pengcheng Wang, et.al. Dynamic analysis and modeling of rotary swing arm crane [J] Journal of Mechanical Engineering, 2011, 47 (20):34-40.

[8] Yongchun Fang, Pengcheng Wang, Ning Sun, et al. Dynamics Analysis and Nonlinear Control of an Offshore Boom Crane [J]. IEEE Transactions on Industrial Electronics, 2014, 61(1):414-427.

[9] Zhiwei Chen, Yueliang Dong. The basis and example analysis of Adams multi body kinematics simulation. China Water Conservancy and Hydropower Publishing House. 2012.6. 